\title{
ANALISIS SISTEM PENETAPAN PEMUNGUTAN DAN PENAGIHAN PAJAK MINERAL BUKAN LOGAM DAN BATUAN DI KABUPATEN MINAHASA
}

\author{
Christina Wowiling ${ }^{1}$, Grace B Nangoi ${ }^{2}$, Dhullo Afandi ${ }^{3}$ \\ 1,2,3 Jurusan Akuntansi, Fakultas Ekonomi dan Bisnis Universitas Sam Ratulangi, Jl. Kampus Bahu, Manado, \\ 95115, Indonesia \\ E-mail :wowiling.christina@yahoo.com
}

\begin{abstract}
The purpose of this research is to analyze the adequacy of the system of stipulation, collection and collection of non-metal mineral and rock taxes in the Minahasa regency and whether they are in accordance with the applicable laws and regulations. The method used in this study is descriptive qualitative, namely analyzing the adequacy of the tax collection and collection system. At the Regional Tax and Retribution Management Agency (BPPRD), Minahasa Regency implemented a Non-Metal and Rock Mineral Tax collection system using the Self Assessment System where the taxpayer determines the amount of tax owed himself, this system has provisions for taxpayers to be active starting from counting, deposit and report the tax owed yourself. The results of the research show that the non-metal mineral and rock tax collection and collection system is running well and in accordance with the applicable laws and regulations. However, there are still inadequate internal control matters such as not using an application system that has been internally controlled and there are no rules related to integrity and ethical values.
\end{abstract}

Keywords: Non-Metal Mineral and Metalliferous Mineral Tax Collection System, NonMetallic Mineral and Stone Taxes

\section{PENDAHULUAN}

Pajak ialah kontribusi wajib untuk negara oleh orang pribadi atau badan yang sifatnya memaksa berdasarkan Undang-Undang. Penggolongan pajak yaitu pajak daerah dan pusat. Pajak Daerah ialah yang dikelola oleh Pemerintah Daerah yaitu Propinsi dan Kabupaten/Kota. Dalam administrasi berhubungan dengan pajak daerah, dilaksanakan oleh Pemerintah Daerah setempat. Pajak yang harus di perhatiakan pemerintah Kabupaten Minahasa ialah Pajak Mineral Bukan Logam dan Batuan dimana sudah menjadi kebutuhan masyarakat Minahasa untuk menjadi bahan industri atau pembangunan pemukiman di daerah tersebut.

Banyaknya potensi akan bahan galian mineral bukan logam, maka untuk proses pemungutan pajaknya dan dalam prosedur pelaksanakannya harus sesuai dengan aturan perudang-undangan yang berlaku tentang pajak daerah, ini merupakan aspek penting yang harus di perhatikan oleh pemerintah, di mana harus ada internal control dalam pelaksanaan pemungutan pajak mineral bukan logam dan batuan agar nantinya segala sesuatu dalam aspek pelaporan data dapat di pertanggung jawabkan.

\section{TINJAUAN PUSTAKA}

Pengertian Pajak. Pajak ialah pungutan untuk kas negara yang sesuai perundangan, dimana tidak didapat timbal balik jasa yang langsung dapat di tunjukan dan yang di gunakan dalam pembayaran pengeluaran secara umum.

Pengelompokan Pajak. Pajak dapat di pungut berdasarkan :

a.Golongan : Pajak Langsung dan Tidak Langsung

b.Sifatnya : Subjektif dan Objektif 
c.Pemungutan : Pajak Pusat Dan Pajak Daerah

Fungsi Pajak. Fungsi-fungsi pajak ialah berfungsi sebagai anggaran ataupun berupa penerimaan pajak dan sebagai salah satu, antara lain menjadi sumber-sumber dana untuk digunakan pemerintah serta manfaatnya dalam membiayai pengeluaran.

Pajak Daerah. Pajak Daerah ialah kesatuan masyarakat hukum yang mempunyai batas-batas wilayah yang berwenang untuk mengatur, mengurus pemerintahan dan kepentingan rakyat setempat baik menurut prakarsa sendiri sertavberdasarkan aspirasi rakyat.

Pendapatan Asli Daerah. Yang menjadi hak sebuah daerah serta diakui untuk menambah suatu nilai akan sebuah kekayaan bersih di periode anggaran tertentu ialah yang di maksud pendapatan daerah.

\section{Dasar Hukum}

1. Dasar hukum pemungutan Pajak Daerah dan Retribusi Daerah adalah Undang-Undang No. 28 Tahun 2009 tentang Pajak daerah dan Retribusi Daerah.

2. UU No. 28 Tahun 2009 Pasal 60 yaitu, tarif pajak mineral bukan logam dan batuan paling tinggi di punggut sebesar $25 \%$.

3. Peraturan Pemerintah Republik Indonesia No. 91 Tahun 2010 yaitu tentang Jenis Pajak Daerah.

4. Peraturan Bupati Minahasa Nomor 6 Tahun 2011 tentang Sistem, Prosedur, dan Sanksi Pemungutan Pajak Daerah Kabupaten Minahasa.

\section{Ciri-ciri pajak daerah}

1. Pajak Daerah asalnya bisa dari PAD atau pajak negara yang telah diserahkan atas daerah sebagai pajak daerah.

2. Dipungut oleh daerah wilayah administratif.

3. Hasil akan pungutan digunakan untuk biaya pengeluaran daerah.

\section{Jenis pajak dan objek pajak.}

jenis pajak dan objek pajak ialah :

1. Pajak Provinsi ialah: Pajak Kendaraan Bermotor, Bea Balik Nama Kendaraan Bermotor, dan lain sebagainya.

2. Pajak Kabupaten/Kota ialah: Pajak Hotel, Pajak Restoran dan lain sebagainya.

\section{Pemungutan Pajak}

Menurut (Mardiasmo, 2018) pemungutan pajak :

1. Official Assessment System ialah system pungutan yang di mana wewenangnya di tentukan oleh pemerintah.

2. Self Assessment System ialah system pungutan di tentukan oleh wajib pajak sendiri.

3. With Holding System ialah system pungutan di tentukan oleh pihak ketiga.

\section{Asas Pemungutan Pajak}

1. Asas Domisili dimana negara mempunyai hak-hak pajak untuk semua pengahsilan dari wajib pajak yang berdomisili di daerahnya atau luar negeri.

2. Asas Sumber yaitu di mana negara berhak memungut pengahasilan di wilayah tersebut.

3. Asas Kebangsaan di peruntukan sesuai dengan kebangsaan.

Penagihan Pajak. Penagihan pajak adalah serangkaian tindakan agar wajib pajak melunasi utang pajaknya.

Jenis-Jenis Pajak Daerah. Menurut (Mardiasmo 2018) Pajak Daerah dibagi mnejadi 2 bagian, yaitu Pajak Provinsi dan Pajak Kabupaten/Kota.

Pengertian Pajak Mineral Logam Dan Batuan. Pajak MBLB ialah pajak untuk sebuah kegiatan pengambilan mineral bukan logam dan batuan, yang bersumber dari alam baik itu di dalam atau pada permukaan bumi untuk dimanfaatkan (Aqualdo, (2013)

Aturan Pajak Mineral Bukan Logam dan Batuan. Undang-Undang No.28 Tahun 2009 Pasal 60 menyatakan bahwa, tarif pajak mineral bukan logam dan batuan ditetapkan paling tinggi sebesar 25\% (dua puluh lima persen). (Lasut, 2004). Objek Pajak MBLB yaitu : 


\begin{tabular}{ll}
\hline Asbes & Leusit \\
Batu Tulis & Magnesit \\
Batu setngah permata & Mika \\
Batu Kapur & Marmer \\
Batu Apung & Nitrat \\
Batu Permata & Opisiden \\
Bentonit & Oker \\
Dolomit & Pasir dan Kerikil \\
Feldspar & Pasir Kuarsa \\
Garam Batu & Perlit \\
Granit & Photspat \\
Grafit & Talk \\
Gipts & Tanah Serap \\
Kalsit & Tanah Diatome \\
Kaolin & Tanah Liat \\
Tras & Tawas (Alum) \\
Yarisif & Basal \\
Zeolit & Trakit dan Mineral Bukan Logam \\
Dasar Pengenaan & Pajak \\
\hline
\end{tabular}

Dasar Pengenaan Pajak Mineral Bukan Logam dan Batuan (Afriana, 2016)

1. Dasar Pengenaan Pajak ialah berupa nilai jual hasil dari bahan galian MBLB.

2. Nilai Jual

3. Nilai pasar

4. Harga Pasar/Nilai Pasar digunakan harga standar untuk tiap jenis mineral bukan logam dan batuan

Sistem Pengendalian Internal. Sistem adalah rangakaiam dari pada urutan kerja serta prosedur nantinya akan terbentuk sebuah pola dan mengatur pelaksanaan kerja dan prosedurprosedur kerja yang saling ada kaitannya untuk menunjukan adanya jalan yang harus di capai dalam menyelesaikan bagian pekerjaan (Gimon, 2018)

Unsur-Unsur Sistem Pengendalian Internal. Internal Control menurut COSO (2013: 4) ialah proses yang telah dijalankan baik oleh dewan direksi maupun manajemen bahkan staff, dalam pembuatan reasonable assurance berkaitan dengan : (a) efektif akan efisien operasional; (b) pelaporan keuangan; dan (c) kepatuhan atas unsur-unsur hukum. Menurut COSO framework, internal control terdiri dari 5 komponen yang saling terkait, yaitu: (1) lingkungan pengendalian; (2) penaksiran risiko; (3) aktivitas pengendalian; (4) informasi dan komunikasi; dan (5) pemantauan.

Sistem Pemungutan Pajak Daerah di Kabupaten Minahasa. Khusus Pajak MBLB di atur dalam Perbu No 6 tahun 2011 pasal 14 ayat (1) sampai (7)

\section{METODE PENELITIAN}

Jenis Penelitian. Hasil penelitian terdapat klasifikasi berupa sebuah sudut pandang. Melihat sebuah sudut pandang ataupun jenis dari sebuah analisis data ialah berdasarkan tujuan dan metode pendekatan. Metodologi penelitian adalah cara ilmiah (rasional, empiris, dan sistematis) yang digunakan oleh pelaku suatu disiplin ilmu untuk melakukan penelitian (Sujarweni, 2015: 10).

Tempat Penelitian. Penelitian dilaksanakan di Badan Pengelola Pajak dan Retribusi Kabupaten Minahasa.

Waktu Penelitian. Penelitian ini dilakukan dari bulan febuari sampai dengan april 2018.

Prosedur Penelitian. Adapun prosedur penelitian yang digunakan antara lain ialah :

1. Lakukan pengkajian dalam studi literature dan studi kepustakaan ataupun mencari referensi dari situs online. 
2. Melakukan pengidentifikasian, merumuskan.

3. Pembatasan masalah.

4. Dilakukan survei.

5. Pengumpulan data.

6. Dilakukan olah data

Metode Pengumpulan Data..Untuk teknik mengumpulkan data, ada langkah-langkah yang lebih strategis karena sesungguhnya yang menjadi tujuan inti dari penelitian ialah mendapatkan data. Sugiyono (2013:224).

Teknik Pengumpulan Data. Teknik yang digunakan penulis dalam pengumpulan data adalah sebagai berikut :

1. Wawancara dilakukan dengan tanya jawab dan diskusi langsung dengan pihak yang ditunjuk Badan Pengelola Pajak dan Retribusi Daerah Kabupaten Minahasa.

2. Dokumentasi, dengan mengumpulkan data secara langsung di kantor Badan Pengelola Pajak Dan Retribusi Daerah Kabupaten Minahasa.

Metode Analisis Data. Metode untuk analisis data akan digunakan ialah metode analisis deskriptif, dimana untuk dapat mengumpulkan, menyusun dan mengananalisis yang nantinya akan memberikan keterangan lengkap untuk masalah yang di hadapi :

1. Menganalisis sistem pengendalian internal atas penetapan, pemugutan, penagihan pajak MBLB untuk menghasilkan bukti transaksi dengan menggunakan teori pengendalian internal menurut COSO.

2. Analisis kepatuhan sistem penetapan, pemungutan, dan penagihan di hubungkan dengan peraturan perundangan yang berlaku. Dalam analisis kepatuhan di gunakan peraturan berupa Peraturan Daerah (PERDA) dan Peraturan Bupati (PERBU). Hal ini di jadikan Rujukan karena ke dua aturan tersebut, merupakan acuan pelaksanaan penetapan dan pemungutan pajak dan retribusi.

\section{HASIL ANALISIS DAN PEMBAHASAN}

4.1. Hasil Analisis

1. Sistem Penetapan Pajak Mineral Bukan Logam dan Batuan Di Kabupaten Minahasa

Penetapan. Kabupaten Minahasa menetapkan tarif Pajak Mineral Bukan Logam dan Batuan yang dipungut sebesar 20\% berdasarkan PERDA No 1 tahun 2011 pasal 15 ayat (5). Prosedur yang di laksanakan Badan Pengelola Pajak dan Retribusi Daerah Kabupaten Minahasa hingga dikeluarkannya surat ketetapan pajak daerah (SKPD):

1. Wajib Pajak mengambil, mengisi, menghitung dan melaporkan sendiri formulir (SPTPD).

2. Kemudian WP menyampaiakan (SPTPD) ke BPPRD kabupaten Minahasa.

3. Petugas menerima document surat permohonan pajak daerah SPTPD dari wajib pajak, kemudian melakukan proses :

a. Petugas memeriksa kebenaran dokumen.

b. Petugas memeriksa keapsahan data.

c. Petugas memiliki formulir cek list (di centang jika sudah lengkap atau tidak)

4. Kemudian petugas seksi pajak membuatkan surat ketetapan pajak daerah (SKPD) dan surat tanda setoran (STS) yang di tanda tangani oleh kepala BPPRD.

5. Petugas kemudian menyerahkan surat tanda setoran (STS) dan surat ketetapan pajak daerah (SKPD) kepada wajib pajak.

6. Selanjutnya wajib pajak tinggal membayar pajak ke bank yang di tunjuk. 
$20 \%$

Rumus Perhitungan : (Volume/Tonase hasil pengambilan $\mathbf{x}$ Nilai Pasar) $\mathbf{x}$

$$
\begin{aligned}
& \text { Contoh Perhitungan : } \\
& \begin{array}{ll}
\text { Pasir 2rit/truk } & =8 \mathrm{~m}^{3} \times \mathrm{Rp} .16 .000=\mathrm{Rp} .128 .000,- \\
\text { Tarif pajak } & =\mathrm{Rp} .128 .000,-\mathrm{x} 20 \%=\mathrm{Rp} .25 .600,-
\end{array} \\
& \begin{array}{ll}
\text { Tanah 3rit/truk } & =12 \mathrm{~m}^{3} \times \mathrm{Rp} .10 .000,-=\mathrm{Rp} .120 .000,- \\
\text { Tarif pajak } & =\mathrm{Rp} .120 .000-20 \%=\mathrm{Rp} .24 .000,-
\end{array}
\end{aligned}
$$

Sistem pemungutan pajak mineral bukan logam dan batuan di Kabupaten Minahasa. Sistem pemungutan yang terdapat pada Badan Pengelola Pajak dan Retribusi Daerah Minahasa juga mengunakan system self assesment, yaitu dimana di dalam proses pembayaran pajak mineral bukan logam dan batuan dilakukan oleh wajib pajak itu sendiri yang berdasarkan pada PERDA No 1 Tahun 2011 pasal 24 tentang tata cara pemungutan.

Tata cara pembayaran dan penagiahan pajak mineral bukan logam dan batuan di Kabupaten Minahasa :

1. Wajib Pajak baik perorangan atau badan mengambil formulir surat pemberitahuan pajak daerah (SPTPD) di Loket Badan Pengelola Pajak dan Retribusi Daerah Minahasa

a. Untuk tiap WP haruslah mengisi SPTPD

b. SPTPD haruslah disampaikan paling lambat 15 hari terhitung saat berakhirnya masa pajak.

2. Wajib Pajak mengisi formulir SPTPD (Surat Pemberitahuan Pajak Daerah) sendiri sesuai dengan perhitungan pungutan pajak MBLB di kabupaten Minahasa yaitu 20\% sesuai Perda yang berlaku dari nilai jual hasil pengambilan bahan galian, dan menandatangani formulir tersebut.

3. Setelah itu wajib pajak menyampaikan Surat Pemberitahuan Pajak Daerah (SPTPD) ke BPPRD

4. Kemudian petugas BPPRD membuatkan Surat Ketetapan Pajak Daerah (SKPD) dan di tanda tangani oleh ketua BPPRD.

5. Petugas membuatkan Surat Tanda Setoran (STS).

6. Wajib pajak melakukan pembayaran pajak dengan Surat Tanda Setoran (STS), Surat Ketetapan Daerah (SKPD) dan slip setoran tersebut ke Bank Sulut Tondano, dan menyetorkan uang sesuai jumlah pajak terutang yang sudah di tetapkan.

7. Setelah wajib pajak selesai melakukan pembayaran, wajib pajak menyerahkan atau melaporkan kembali bukti pembayaran pajak yang di lampiri Surat Tanda Setoran (STS) ke BPPRD kabupaten Minahasa. Surat tanda setoran (STS) dibuat rangkap (6) dengan distribusi sebagai berikut : (1) Kasir; (2) Pemegang Kas - Unit Organisasi; (3) KASDA; (4) Fungsi Pembukuan atau Akuntansi; (5) BUD; dan (6) Arsip Dinas Pendapaan (dilampiri Slip Setoran Bank)

8. Petugas seksi pajak BPPRD menyerahkan SKPD dan STS kepada wajib pajak, kemudian lembaran lainnya akan di arsipkan.

Sistem Penagihan Pajak Mineral Bukan Logam Dan Batuan Di Kabupaten Minahasa. Pelaksanaan dalam penagihan dilakukan terhadap wajib pajak dan menerbitkan surat tagihan pajak daerah (STPD) oleh kepala daerah sesuai PERDA No 1 Tahun 2011 pasal 27 ayat (1).

\subsection{Pembahasan}

1. Analisis sistem penetapan pajak mineral bukan logam dan batuan di Kabupaten Minahasa

Dilakukan pendekatan analisis yaitu berupa pengujian sistem pengendaian internal serta kepatuhan terhadap peraturan perundangan yang berlaku. 
Analisis Sistem Pengendalian Internal. Sistem pengendalian internal menurut COSO harus memenuhi unsur-unsur pengendalian lingkungan, penaksiran resiko, aktivitas pengendalian, informasi dan komunikasi, dan pemantauan/monitoring, hal ini jika dilakukan analisis lebih lanjut terhadap sistem pengendalian internal pada prosedur penetapan di peroleh hal-hal sebagai berikut :

- Analisis Lingkungan Pengendalian Sistem Penetapan Pajak Mineral Bukan Logam dan Batuan. Penempatan personil di organisasi sehubungan dengan penetapan pajak daerah, di dasarkan pada kompetensi yang di miliki sesuai dengan syarat-syarat seseorang menduduki jabatan/tugas tertentu yang di atur dalam peraturan PERBU Kabupaten Minahasa.

- Analisis Penaksiraan Resiko Sistem Penetapan Pajak Mineral Bukan Logam dan Batuan. Unsur-unsur penaksiran resiko adalah untuk membentuk berupa dasar yang nantinya menentukan bagaimana risiko tersebut akan dikelola. Unsurunsur yang tidak terpenuhi di Badan Pengelola Pajak dan Retribusi Daerah Minahasa, yaitu tidak adanya suatu sistem yang dapat menangani resiko jika terjadi suatu perubahan kebijakan organisasi.

- Analisis Aktivitas Pengendalian Prosedur Sistem Penetapan Pajak Mineral Bukan Logam dan Batuan. Badan Pengelola Pajak Dan Retribusi Daerah Minahasa, telah melaksanakan pengendalian di mana setiap kejadian, transaksi dan pemeriksaan kelengkapan document sebelum mengeluarkan surat ketetapan daerah (SKPD) di sertai otoritas dari pihak yang berwenang, untuk mencegah terjadinya penyimpangan. Akan tetapi Badan Pengelola Pajak Dan Retribusi Daerah Kabupaten Minahasa tidak mengikuti pemisahan tugas yang tersusun dalam uraian tugas.

- Analisis Informasi Dan Komunikasi Sistem Penetapan Pajak Mineral Bukan Logam dan Batuan. Pada Badan Pengelola Pajak MBLB di terapkan sistem pemrosesan data yang masih manual, sehingga sistem informasi dan komunikasi belum relevan dalam pelaporan data. Di katakan belum relevan karena tidak terpenuhinya unsur-unsur informasi dan komunikasi menurut teori COSO.

- Analisis Pemantauan / Monitoring Sistem Penetapan Pajak Mineral Bukan Logam dan Batuan. Badan Pengelola Pajak Dan Retribusi Daerah Kabupaten Minahasa tidak melakukan pemantauan dan pengawasan khusus pada bidang pendataan, pendaftraan, dan penetapan dalam upaya mengoptimalisasikan penerimaan pajak daerah kabupaten Minahasa.

2. Analisis Kepatuhan Sistem Penetapan Pajak Mineral Bukan Logam dan Batuan Sesuai hasil analisis yang di lakukan terhadap sistem dan prosedur penetapan pajak yang dilakukan oleh Badan Pengelola Pajak Dan Retribusi Daerah Minahasa jika di hubungkan dengan peraturan perundang-undangan yang di maksud terdapat hal-hal yang telah di penuhi sebagai berikut :

1. Badan Pengelola Pajak Dan Retribusi Daerah Kabupaten Minahasa menetapkan jumlah tarif pajak MBLB di pungut $20 \%$ besarnya. Penetapan ini di tandai dengan adanya surat ketetapan pajak daerah (SKPD) yang berisikan informasi rinci tentang jumlah hasil produksi dikalikan dengan tarif 20\%. dan setelah itu di buatkan Surat Tanda Setoran (STS). Hal ini jika di lihat berdasarkan Peraturan Daerah no 1 Tahun 2011 pasal 15 ayat (5) menyebutkan bahwa tarif pajak MBLB di tetapkan besarnya ialah 20\%. Peraturan Pemerintah juga menyebutkan sebelum di buatkan Surat Setoran harus di buat Surat Ketetapan Retribusi Daerah, di mana wajib pajak harus mengisi formulir (SPTPD) yang berpedoman pada Perda no 1 Tahun 2011 pasal 15 ayat (1) sampai (7) tentang dasar pengenaan dan tarif pajak serta wilayah pemungutan. 
2. Setelah Badan Pengelola Pajak Dan Retribusi Daerah Kabupaten Minahasa mengelurkan surat ketetapan pajak daerah (SKPD), wajib pajak harus menyetorkan pajak MBLB ke Bank yang di tunjuk paling lambat tanggal 10 setelah berkhirnya masa pajak. Hal ini jika di lihan berdasarkan Peraturan Bupati no 6 tahun 2011 pasal 14 ayat (1) menyatakan pajak mineral bukan logam dan batuan di setorkan wajib pajak setiap awal bulan setelah berkhirnya masa pajak.

3. Analisis sistem pemungutan dan penagihan pajak mineral bukan logam dan batuan di Kabupaten Minahasa

Pembahasan ini untuk mengukur memadai tidaknya sistem dan prosedur pemungutan dan penagihan pajak MBLB daerah Minahasa, dilakukan pendekatan analisis yaitu dengan pengujian sistem pengendaian internal serta kepatuhan terhadap peraturan perundangan yang berlaku.

Analisis Sistem Pengendalian Internal. Hal ini jika dilakukan analisis lebih lanjut terhadap sistem pengendalian internal pada prosedur penetapan di peroleh hal-hal sebagai berikut :

- Analisis Lingkungan Pengendalian Sistem Pemungutan dan Penagihan Pajak Mineral Bukan Logam dan Batuan

Penempatan personil di dalam organisasi sehubungan dengan ditetapkan pajak daerah, di dasarkan pada kompetensi yang di miliki sesuai dengan syarat-syarat seseorang menduduki jabatan/tugas tertentu yang di atur dalam peraturan PERBU Kabupaten Minahasa No 36 tahun 2016 Tentang Penetapan, Kedudukan, Susunan Organisasi, Tugas Dan Fungsi Serta Tata Kerja dan PERDA NO 3 Tahun 2008 tentang organisasi dan tata kerja dinas daerah (lembaran daerah kabupaten Minahasa tahun 2008 no 9). Badan Pengelola Pajak Dan Retrubusi Daerah Minahasa juga menerapkan kerahasiaan perpaajakan. Hal ini merupakan hak pembayar pajak untuk diberikan perlindungan kerahasiaan oleh administasi perpajakan pemerintah, atas segala informasi perpajakan yang diserahkan dalam pemenuhan kewajiban perpajakan, yang tunduk pada PERDA no 1 tahun 2011 pasal 41 ayat (1) sampai (6) tentang ketentuan umum, berisikan bahwa setiap pejabat atau petugas dilarang memberiahukan kepada pihak lain segala sesuatu yang di ketahui berhubungan dengan data wajib pajak. Hal-hal tersebut di atas menggabarkan terpenuhinya proses lingkungan pengendalian menurut teori COSO.

- Analisis Penaksiraan Resiko Sistem Pemungutan dan Penagihan Pajak Mineral Bukan Logam dan Batuan

BPPRD menerapkan sistem pemungutan dan penagihan pajak MBLB di Minahasa dengan hanya menerima bukti pembayaran berupa slip pembayaran bank, yang nantinya akan di arsipkan sebagimana untuk menunjang administrasi laporan penerimaan pajak daerah.

- Analisis Aktivitas Pengendalian Sistem Pemungutan dan Penagihan Pajak Mineral Bukan Logam dan Batuan

Sehubungan dengan aktivitas pengendalian Badan Pengelola Pajak Dan Retribusi Daerah Minahasa, telah melaksanakan pengendalian berdasarkan tugas masingmasing bidang di mana sebelum adanya transaksi pembayaran oleh wajib pajak, sudah melewati tahapan kelengkapan dokumen, pengisian surat pemberitahuan pajak daerah, kemudian di keluarkan surat ketetapan pajak, barulah wajib pajak akan menyetorkan sesuai nilai yang terbilang pada surat ketetapan ke bank yang di tunjuk.

- Analisis Informasi Dan Komunikasi Sistem Pemungutan dan Penagihan Pajak Mineral Bukan Logam dan Batuan 
Sistem informasi dan komunikasi adalah pengelolahan akuntansi yang di cakup sejak di mulai sampai akhir, termasuk berupa alat-alat elektronik. Pada BPPRD Kabupaten Minahasa di terapkan sistem pemrosesan data dalam pencetakan SPTPD, SKPD, STS dan lainya menggunakan komputer, sedangkan dalam proses pencatatan penerimaan dari pungutan dan penagihan pajak di lakukan secara pembukuan manual tanpa adanya sistem aplikasi.

- Analisis Pemantauan / Monitoring Sistem Pemungutan dan Penagihan Pajak Mineral Bukan Logam dan Batuan

Tindakan pemantauan berupa jika wajib pajak telah melewati tanggal jatuh tempo pembayaran dan penyetoran pajak paling lama 30 hari setelah saat terutang pajak, maka Badan Pengelola Pajak Dan Retribusi Daerah Kabupaten Minahasa mengeluarkan surat tagihan pajak daerah (STPD) dan di kenakan denda bungan $2 \%$ per bulan.

4. Analisis Kepatuhan Sistem Pemungutan dan Penagihan Pajak Mineral Bukan Logam dan Batuan

Pemungutan dan penagihan pajak MBLB di Kabupaten Minahasa di kelolah Badan Pengelola Pajak Dan Retribusi Daerah Kabupaten Minahasa sudah memadai jika di hubungkan dengan peraturan perundang-undangan yang di maksud terdapat hal-hal yang telah di penuhi sebagai berikut :

1. Badan Pengelola Pajak dan Retribusi Daerah Kabupaten Minahasa menerapkan aturan pemungutan pajak dengan system self assesment, di mana memberi kepercayaan penuh kepada wajib pajak untuk menghitung, membayar dan melaporkan sendiri pajak mineral bukan logam dan batuan.

2. Dikeluarkan surat tagihan pajak daerah (STPD) oleh Badan Pengelola Pajak Dan Retribusi Daerah Kabupaten Minahasa jika terjadi pajak kurang bayar, wajib pajak dikenakan sanksi administrative berupa bunga atau denda, atau terjadi salah hitung, salah tulis berdasarkan hasil pemeriksaan pajak.

3. Pelaksanaan dalam penagihan ini dilakukan terhadap wajib pajak yang sampai batas waktu dalam amanat PERBU NO 6 Tahun 2011 pasal 14 dibayarkan paling lambat tgl 10 stelah berakhirnya bulan masa pajak, misalnya "masa pajak bulan januari 2011, jatuh tempo pajak terhadap terutang adalah 10 febuari 2011". Setelah jatuh tempo yang di maksud akan di berikan surat teguran denda $2 \%$.

\section{KESIMPULAN DAN SARAN}

\subsection{Kesimpulan}

Berdasarkan hasil pembahasan maka dapat ditarik kesimpulan sebagai berikut:

1. Sistem penetapan Pajak MBLB pada Badan Pengelola Pajak Dan Retribusi Daerah Minahasa terdapat hal-hal yang belum sepenuhnya sesuai dengan internal control seperti dalam lingkungan pengendalian masih belum nampak hal-hal yang berhubungan dengan integritas dan nilai etik.

2. Sistem pemungutan dan penagihan Pajak MBLM terdapat beberapa hal yang sudah sesuai, akan tetapi masih terdapat hal-hal yang belum sepenuhnya sesuai dengan internal control yakni dalam penaksiran resiko yaitu untuk membentuk suatu dasar untuk menentukan bagaimana risiko harus dikelola, sistem informasi dan komunikasi yang belum memadai yaitu pengelolahan akuntansi berbasis sistem aplikasi.

3. Sistem penetapan, pemungutan dan penagihan pajak mineral bukan logam dan batuan pada BPPRD Minahasa sudah sesuai dengan aturan perundang-undangan perpajakan (Peraturan Daerah dan Peraturan Bupati Minahasa). 


\subsection{Saran}

1. Harus ada pedoman yang dilakukan petugas-petugas jika terjadi perubahan kebijakan, dan jika ada perubahan atau penggantian pegawai harus di gantikan dengan pegawai yang memiliki kemampuan yang sama, di mana baiknya di terapkan prosedur pendampingan pegawai baru.

2. Saran untuk Badan Pengelola Pajak Dan Retribusi Daerah Minahasa, agar mulai beralih menggunakan sistem teknologi berbasis aplikasi pengelola data, untuk menunjang kinerja yang berhubungan dengan proses verifikasi data wajib pajak.

\section{DAFTAR PUSTAKA}

Andela R, (2013). Anlisis Pemungutan Pajak Hotel Pada Dinas Pendapatan Daerah Kabupaten Kuantan Singingi.

Aqualdo N (2013), Potensi Penerimaan Pajak Mineral Bukan Logam Dan Batuan Di Kabupaten Rokan HuluTahun 2007-2012. Jurnal Ekonomi Vol 21, No3

Afriana S, P (2016), Optimalisasi Pemungutan Pajak Mineral Bukan Logam dan Batuan dalam rangka peningkatan Pendapatan Asli Daerah Kabupaten Tanah Bumbu.

COSO. 2013. Internal Control - Integrated Framework : Executive Summary, Durham, North Carolina, May 2013

Gerger C G, Dkk (2014). Menentukan Faktor-faktor yang mempengaruhi pembayarn pajak perspektif tentang administrasi pajak. International Journal of economics and Finance Studies. Vol 6 No 1. Hal-19

Gimon H (2018), Analisis Sistem Akuntansi Pelaksanaan APBDes Pada Pemerintah Desa

Kopandakan I Kecamatan Kotamobagu Selatan Kota Kotamobagu

Korua D (2015). Analisis Efektivitas Dan Kontribusi Penagihan Pajak Secara Aktiv Terhadap Pencairan Tunggakan Pajak.

Lasut I, P (2014). Efektivitas Penerimaan Pajak Pengambilan dan Pengeloalaan Mineral bukan Logam dan Batuan sebagai sumber Pendapatan Asli Daerah Kota Tomohon. Vol. 2 No 4 Des 2014, Hal 732-742

Mardiasmo (2018), Perpajakan Edisi Terbaru 2018. Penerbit Andi. Yogyakarta.

Sujarweni, V Wiratna. 2015. Metodologi Penelitian : Bisnis \& Ekonomi. Cetakan Pertama. Pustaka Baru Press. Yogyakarta.

Sugiyono (2013). Metode Penelitian Pendidikan Pendekatan Kuantitatif, Kualitatif, dan R\&D. Bandung: Alfabeta.

Tesalonika Moningka (2016). Analisis Potensi Dan Efektivitas Peneriman Dan Pemungutan Pajak Mineral Bukan Logam Dan Batuan Sebagai Sumber Pendapatan Asli Daerah (PAD) Di Kabupaten Minahasa Utara 